\title{
Curse of La Corona: unravelling the scientific and psychological conundrums of the 21 st century pandemic
}

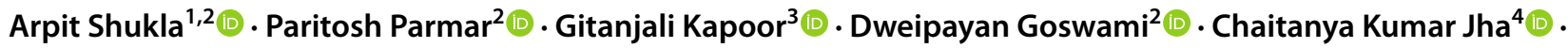 \\ Baldev Patel $^{2} \cdot$ Meenu Saraf ${ }^{2}$ (D)
}

Received: 3 November 2020 / Accepted: 28 November 2020 / Published online: 4 January 2021

(c) The Author(s), under exclusive licence to Springer Nature Switzerland AG part of Springer Nature 2021

\begin{abstract}
Microbes possess a tremendous potential to interact with their surroundings and have continued to shape the future of all life forms existing on earth. Of all the groups of microbes, viruses are the most nefarious creatures which cannot be solely classified as living or non-living but still pose the greatest threats to the biosphere. Viruses are minuscule, diverse and are probably the only entities that exhibit non-mutualistic association with other lifeforms while retaining their ability to infect and hijack any of the existing living being on the planet. The latest global devastation, caused by novel SARS-CoV-2, is unparalleled in the last century. This review encompasses the mysterious origin of this virus by tracking its lineage, which may help to decode the conundrum of SARS-CoV-2 and shed more light on its epidemiology. The implications and the challenge posed by this virus to the scientific community to the medical community and the economy at large are reflected. Also discussed is the paradigm shift brought upon by the COVID-19 pandemic on the human psyche and their behaviour.
\end{abstract}

Meenu Saraf

msaraf@gujaratuniversity.ac.in

Arpit Shukla

ashukla@gujaratunivesity.ac.in; arpit.shukla@iar.ac

Paritosh Parmar

paritoshparmar@gujaratuniversity.ac.in

Gitanjali Kapoor

gitanjalikapoor@gujaratuniversity.ac.in

Dweipayan Goswami

dweipayan.goswami@gujaratuniversity.ac.in

Chaitanya Kumar Jha

chaitanyakjha@gmail.com

Baldev Patel

patelbaldev56@yahoo.in
1 Department of Biological Sciences and Biotechnology, Institute of Advanced Research, University of Innovation, Koba Institutional Area, Gandhinagar, Gujarat 382426, India

2 Department of Microbiology and Biotechnology, University School of Sciences, Gujarat University, Ahmedabad, Gujarat 380009, India

3 Department of Psychology, University School of Psychology, Philosophy and Education, Gujarat University, Ahmedabad, Gujarat 380009, India

4 Microbiology Department, Gujarat Arts and Science College, Ahmedabad, Gujarat 380006, India 


\section{Graphic Abstract}

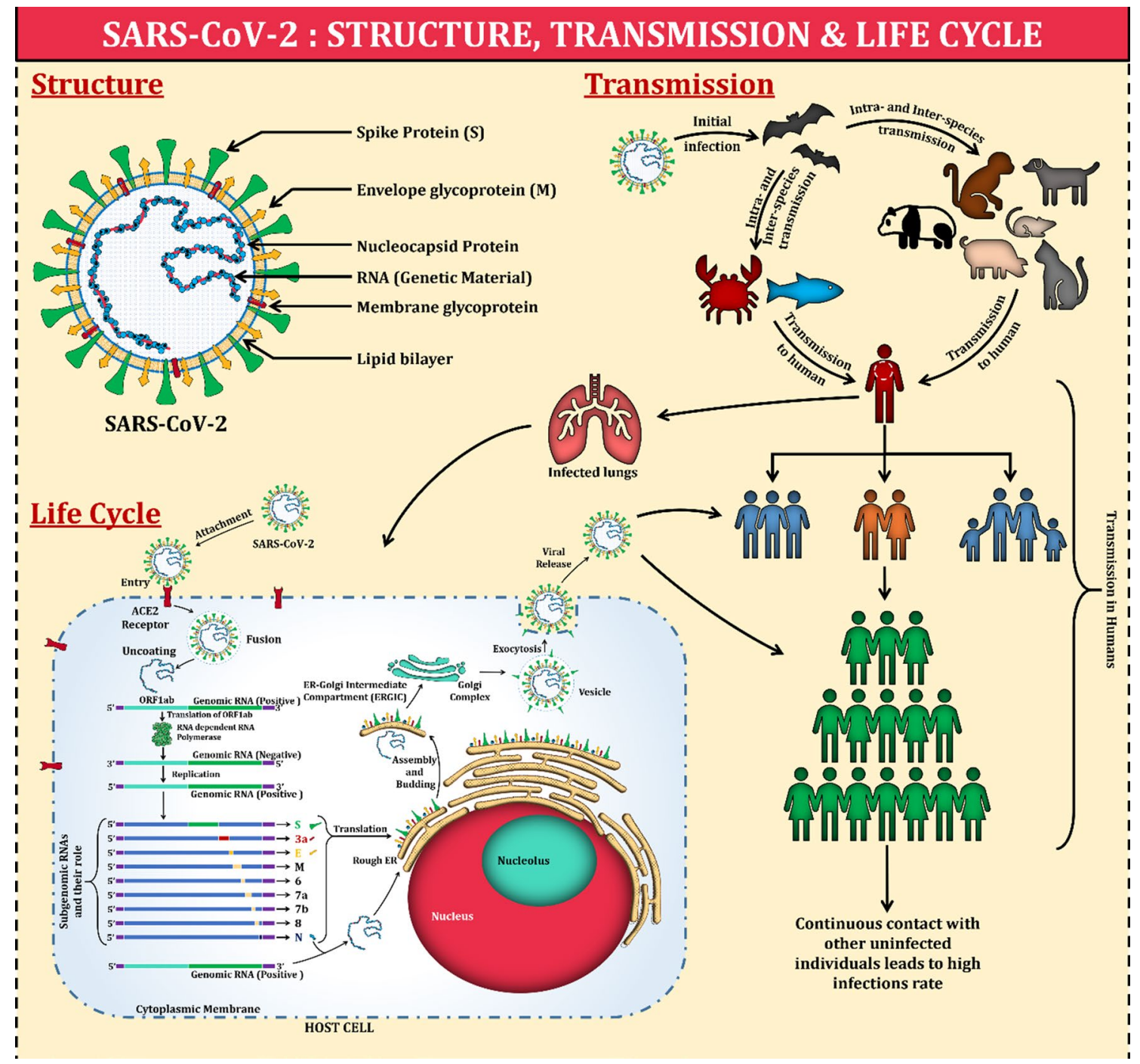

Keywords SARS-CoV-2 $\cdot$ Coronavirus $\cdot$ Lineage of SARS-CoV-2 $\cdot$ Pandemic $\cdot$ Microbiology

\section{Introduction}

\section{COVID-19}

The dawn of 2020 witnessed the world brought to a virtual standstill with the outbreak of a novel severe acute respiratory syndrome virus (SARS-CoV-2). The outbreak of SARS$\mathrm{CoV}-2$ is thought to have originated during the last quarter of 2019, which soon became endemic and epidemic, by swiftly increasing its infection coverage region across China by December 2019 and January 2020. The exponential spread of the virus and the inefficiency of the administration to curb, quarantine or isolate the coronavirus disease (COVID19)-infected personnel led to its ultimate declaration as a global pandemic, on 11 March 2020 by the World Health Organization. As on 28 April 2020, more than 50 million confirmed cases in 220 countries/territories were identified to be infected with the deadly SARS-CoV-2, accounting for more than 1 million deaths globally [1].

\section{Origin and spread}

In 2002, China reported the first human infection by $\mathrm{CoV}$ of animal origin and later termed SARS-CoV, the epidemic spread across 26 countries and more than 8000 cases in 2003. The transmission of SARS-CoV was from person to person. A prophylactic cure for SARS-CoV is still under development [2]. Towards the concluding months of 2019, 
a novel CoV-2 had emerged, infecting adults in Wuhan, China. Initial cases involved interaction of individuals with the Huanan wholesale life stock and seafood market. The patients were admitted with complaints of severe pneumonia. Upon aetiological investigations, the Chinese authorities reported isolation of a novel $\mathrm{CoV}(\mathrm{nCoV})$ and subsequently the WHO named the virus SARS-CoV-2 while disease was termed COVID-19 [3]. The virus is said to have originated from the seafood and life stock trading market of Wuhan [4].

\section{Corona Viruses (CoV)}

Viruses are obligate parasites and are powerless without a host. Their notoriety lies in their ability to hijack the host machinery and use it to produce more viral particles, thereby rendering the host helpless and powerless. In 2006 and 2009, Neuman et al. and Bárcena et al. [5, 6] were the first to reveal the structural features of $\mathrm{CoV}$, based on electron microscopy. The basic features of the virion particles depicted that they had a spherical shape with an average diameter of $125 \mathrm{~nm}$. The signature trait of these viral particles is the protruding club-shaped spike projections emanating from its surface, resembling solar corona appearance which ultimately led to its name-Coronaviruses $(\mathrm{CoV})$. Besides the crown shape, members of $\mathrm{CoV}$ genus are known to be pleomorphic [3]. The envelope of this virus is composed of a lipid bilayer membrane in which several transmembrane proteins are embedded. In the central core of this virus, its brain in the form of a single-stranded RNA, consisting of 25 to 33 kilobases $(\mathrm{kb})$, which is the largest among RNA viruses, bound to few nucleocapsid phosphoproteins. Spike (S) protein is the most important for this virus to infect a human, which very effectively interacts with the human angiotensin-converting enzyme 2 receptor found in the alveoli of the human lungs. Adjacent to this, their exist hemagglutinin-acetylesterase and membrane glycoprotein glycoproteins, which collectively help S-proteins to efficiently interact with its receptor. A small envelope glycoprotein also exists, embedded in the viral membrane, providing stability to the viral structure [7]. There also exist several structural, accessory, and non-structural proteins in the $\mathrm{CoV}$, which are represented in Table 1. Several CoV identified till date share the same structural features and are bifurcated into four groups based on their genome sequences and serological reactions: alpha $(\alpha)$, beta $(\beta)$, gamma $(\gamma)$ and delta ( $\delta$ ) coronaviruses. $\alpha$ and $\beta-\mathrm{CoV}$ occur naturally in bats and are known to infect mammals, whereas birds are the natural reservoir and primary targets for $\gamma$ and $\delta-\mathrm{CoV}$. The wide range and extended outreach of bat and bird species has led to extensive mutations, which is responsible for the distribution of $\mathrm{CoV}$ (Woo et al. 2012).

The human CoV NL63 and bat CoV ARCoV2 are believed to have evolved from a common ancestor about

Table 1 Structural and accessory proteins in SARS-CoV- 2

\begin{tabular}{|c|c|c|c|c|}
\hline Sr. No. & Protein & $\begin{array}{l}\text { Molecular } \\
\text { weight } \\
(\mathrm{kDa})\end{array}$ & Role/significance & References \\
\hline \multicolumn{5}{|c|}{ Structural proteins } \\
\hline 01 & Spike $(S)$ & 150 & $\begin{array}{l}\text { Provides characteristic club shape, necessary for binding with angiotensin- } \\
\text { converting enzyme (ACE2) receptor to enter the host cell. }\end{array}$ & [7] \\
\hline 02. & Envelope $(E)$ & $8-12$ & $\begin{array}{l}\text { Facilitates assembly and release of fresh virus particles from host cell while } \\
\text { also being vital for the pathogenesis. }\end{array}$ & \\
\hline 03 & Membrane $(M)$ & $25-30$ & Most abundant protein that provides the circular curve shape. & \\
\hline 04 & Nucleocapsid $(N)$ & $45-6$ & Complex of + single-strand RNA genome and phosphoproteins. & {$[12]$} \\
\hline 05 & Hemagglutinin-esterase $(H E)$ & 65 & $\begin{array}{l}\text { Enhance S-protein-mediated cell entry and virus spread through the } \\
\text { mucosa. }\end{array}$ & {$[12,13]$} \\
\hline \multicolumn{5}{|c|}{ Accessory proteins } \\
\hline 06 & $\begin{array}{l}\text { 3C-like protease or Main } \\
\text { protease }\left(3 \mathrm{CL}^{\text {pro }} \text { or } M^{\text {pro }}\right)\end{array}$ & NA & Trimming of viral protein to render their biological activity. & {$[14,15]$} \\
\hline 07 & Papain-like protease $\left(\mathrm{PL}^{\mathrm{pro}}\right)$ & NA & Trimming of viral protein to render their biological activity. & [14] \\
\hline \multicolumn{5}{|c|}{ Non-structural proteins (nsp) } \\
\hline 08 & nsp 10 & NA & Responsible for replication and packing of this virus & {$[16,17]$} \\
\hline 09 & nsp 12 & NA & RNA-dependent RNA polymerase (RdRp) & \\
\hline 10 & nsp 13 & NA & Helicase & \\
\hline 11 & nsp 14 & NA & $\mathrm{N}$-terminal exoribonuclease and C-terminal guanine-N7 methyl transferase & \\
\hline 12 & nsp 15 & NA & Uridylate-specific endoribonuclease & \\
\hline 13 & nsp 16 & NA & 2'-O-methyltransferase & \\
\hline
\end{tabular}

'NA' Not available 
a 600 y ago. Human CoV 229E and GhanaGrp1 bat CoV diverged from a common ancestor about $350 \mathrm{y}$ ago. The lineage of alpaca $\mathrm{CoV}$ deviated from human $\mathrm{CoV} 229 \mathrm{E}$, more recently about $65 \mathrm{y}$ ago. It was during the same time that the first SARS-CoV was discovered [8]. The virus is thought to have jumped several species of bats, beginning with the infection of leaf-nose bats followed by horseshoe bats and civets before striking humans $[9,10]$. The causative virus for 2012 outbreak of Middle Earth Respiratory Syndrome (MERS), MERS-CoV, is thought to have emerged from bats to humans via camels. The pandemic causing SARS-CoV-2 possesses about $79 \%$ similarity with the previously identified SARS-CoV and 50\% similarity with MERS-CoV, and it is thought to be evolved from bat-SL-CoVZC45 to bat-SLCoVZXC21 [11]. The original lineage and its immediate predecessors are still not confidently identified.

\section{Decoding the conundrum of SARS-CoV-2}

The atypical salient features of SARS-CoV-2 have baffled the scientific community and have posed several pertinent difficult questions. The origin of SARS-CoV-2 was originally thought to be sea food market of Wuhan, China, though the studies have revealed that majority of initial infections were contracted by the individuals which were not exposed to the said origin [12]. Any evidence regarding patient zero, the first individual to be infected with this virus remains a mystery. Several approaches dealing with genetic information of SARS-CoV-2 along with its protein sequences are analysed to pinpoint its origin. This exerts an immense challenge on the health-care workers and researchers since the infected individuals are still highly contagious. Since the first case in October 2019, COVID-19 was declared a pandemic by WHO within roughly six months of its first appearance $[13,14]$. The ability of an infected individual to spread infection is measured by the reproductive number, $\mathrm{R}$-naught $\left(\mathrm{R}_{0}\right)$ value. The $\mathrm{R}_{0}$-value for SARS-CoV-2 is thought to be up to four with a doubling time of seven days, which is not been observed for CoV [15]. This value implies that each infected individual can transmit the virus to four other individuals. Though till date seven $\mathrm{CoV}$ are known to cause human infections, COVID-19 is the first ever pandemic caused by any $\mathrm{CoV}$ and the major culprit responsible for its high infection rate is thought to be a unique combination of amino acids in the spike proteins that possess the ability to infect humans [16]. It is interesting to consider that the novel SARS-CoV-2, believed to have originated from animal, yet possessing a spike protein having tremendous capability to interact with human's ACE2 receptor, has surprised the researchers, making them think about this protein being genetically engineered in the laboratory. Fuelling such speculations is the mysterious origin of this virus.

\section{Lineage of SARS-CoV-2}

Efforts were made to identify the lineage of SARS-CoV-2 by performing and analysing the genome sequence from eight infected patients, among the first group of people to acquire infection linked to sea food market of Wuhan, China [11]. Phylogenetic analysis of these SARS-CoV-2 genomes and those of other $\mathrm{CoV}$ were used to determine evolutionary history of the virus with an aim to infer its likely origin. The genomes of SARS-CoV-2 from the infected humans possess $99.98 \%$ sequence identity and showed $88 \%$ identity to two bat-derived SARS-like coronaviruses, bat-SL-CoVZC45 and bat-SL-CoVZXC21, which are considered to be the closest relatives but show only $79 \%$ similarity with previously identified SARS-CoV (Fig. 2). Protein sequence analysis suggested that nsp7 and E proteins of SARS-CoV-2 have $100 \%$ identity with the same proteins of bat-SL-CoVZC45 [15]. All this information reflects that SARS-CoV-2 is highly similar to bat-SL-CoVZC45 and bat-SL-CoVZXC21 but characteristically distinct from previously identified SARS$\mathrm{CoV}$. More intriguing information regarding SARS-CoV-2 is its infection rate, which is way beyond than exhibited by any other coronavirus, and this ability is attributed to the S-protein, which serves as a clamp to notch with humans ACE2 receptor. S-protein possesses two domains: (i) S1 domain responsible for ACE2 receptor binding and (ii) the S2 domain responsible for cell membrane fusion. The protein sequence analysis of this protein showed to possess much lesser identity to the same protein of its closest known relative, bat-SL-CoVZC45, and shared more similarity with genomic distant relative, SARS-CoV [11, 17]. Phylogenetic genome analysis shows SARS-CoV-2 and SARS-CoV to fall in two widely distinct clades, yet as a nature's miracle, possess 50 important conserved amino acids with absolute identity in the S1 receptor binding domain without any sort of epigenetic mutation. These regions of $\mathrm{S} 1$ domain possessing conserved amino acids are thought to be crucial for its binding with ACE2 [11]. This phenomenon is found to be true only for S-protein, while other proteins of SARSCoV-2 are highly identical to its closest genomic relative, bat-SL-CoVZC45 and not to SARS-CoV. Such similarity can be a reflection of a deliberate genetic manipulation or simply nature's selection; however, recently, Andersen and researchers have strongly hypothesized such attributes of SARS-CoV-2 to nature's architecture [17].

\section{Distinguishing features of SARS-CoV-2}

Genome of SARS-CoV-2 (Fig. 3) is arranged in a manner that allows the synthesis of viral replicase enzyme upon entry into the host cell, thus facilitating replication of viral RNA and subsequently more viral particles [7]. Following the replicase gene are the structural genes, each responsible 
for the vitality, virulence, pathogenicity and proliferation of the virus. S-protein is responsible for the synthesis of spikes on the surface that is characteristic of the virus. The M-protein is responsible for providing the curved shape of the virus, whereas E-protein is the basic envelope that maintains the integrity of the virus. The E-protein also facilitates the assembly and release of the virus from the host which adds to the pathogenicity of the virus [18]. The HE protein facilitates the entry of the viral S-protein-mediated cell entry with the ACE2 receptors found on the human alveoli [19]. Interactions between $\mathrm{N}$-protein, nsp3 and M-protein facilitate the replicase-transcriptase complex (RTC) formation [7].

\section{Stability of SARS-CoV-2}

A study by Chin et al. [20] found the SARS-CoV-2 to be stable in virus transport medium at $\mathrm{pH}$ (3 to 10) and at low temperatures. At $4{ }^{\circ} \mathrm{C}$, the virus inactivation time was about 14 days, which had reduced to $5 \mathrm{~min}$ at $70{ }^{\circ} \mathrm{C}$. This strongly implies the susceptibility of individuals living in an environment that is relatively cooler. The team also studied the stability of virus on various surfaces. The virus culture was pipetted onto the test surface, which was then left at about $22{ }^{\circ} \mathrm{C}$ with $65 \%$ relative humidity before being recovered in the virus transport medium to corroborate retrieval of active virus. It was reported that virus failed to survive for more than three hours on coarse surfaces such as printing and tissue papers, while the virus could remain viable on materials such as wood and cloth even after $24 \mathrm{~h}$. About $0.1 \%$ of the original inoculum was detected to be viable on the outer surface of the surgical even on day seven [21].

\section{Host response}

During the onset of COVID-19, the viral load, which is directly correlated with the age of an individual, is at its maximum which declines subsequently with the activation of host defences and the provided treatment. The high viral load during preliminary phase of the infection is responsible for high infectiousness of the individual, thereby making him highly contagious. It is for this reason that quarantine and isolation have been strictly employed to contain the virus and hinder its transmission. To overcome the immune system, any pathogen would rely mostly on the concentration of the pathogen per host cell infected, and subsequently, heightened viral load also poses a threat of developing resistance to antivirals. Consequently, the host immune system warriors primarily responsible to ward off an incoming infection, $\operatorname{IgG}$ and $\operatorname{IgM}$, increase in concentration as the infection progresses. 'Seroconversion', i.e. the conversion from being seronegative to seropositive, during which specific antibodies develop in blood to detectable limits, in
COVID-19-affected individuals is seen up to 3 weeks from the day of infection. Seroconversion is crucial for proper and accurate diagnosis of an infected individual as the patient, if asymptomatic, maybe still be highly contagious and promote the spread of the virus [22-27].

\section{Clinical features}

The positive single-stranded RNA genome of SARS-CoV-2 allows direct translation of the viral genome in host which further provides an unfair advantage to a virus, which is capable of causing respiratory, hepatic and neurological diseases in humans [28]. Continual replicative and transcriptional errors in addition to RNA-dependent RNA polymerase jumps boost the recombination rates of CoV [29]. A consensus of the clinical features includes dry cough, fever, diarrhoea and vomiting. Recently, loss of smell and taste have served as early indicators of the onset of COVID-19. The clinical features of a person infected with SARS-CoV-2 range from being completely asymptomatic to the requirement of extensive respiratory assistance [12].

COVID-19 manifests an overexuberant inflammatory response, which can be detected by blood tests. The most common laboratory biochemical abnormalities exhibited by a COVID-19 patient are: hypoalbuminemia, lymphopenia, decreased percentage of lymphocytes and neutrophils, elevated C-reactive protein and lactate dehydrogenase, and decreased CD8 count [30]. In some cases, the activity of crucial cardiac enzymes: creatine kinase (CK), myoglobin (MYO), cardiac troponin 1 (Ctn1), brain natriuretic peptide (BNP) and CK myocardial band (CK-MB) were found to be significantly elevated. The chest computed tomography (CT) tests during the progress of COVID-19 are used to study pleural effusion, i.e. the build-up excess fluids between the layers of lung pleura. On progression, an increasing opacity of the lungs signals the spread of pleural effusion, rendering it incapable of transfusing oxygen into the blood [31].

\section{Pathogenesis}

Human angiotensin-converting enzyme (ACE-2), found abundantly on type- 2 pneumocytes in the alveoli, efficiently interacts with the receptor binding domain (RBD) of S-protein of SARS-CoV-2 (Fig. 1). This interaction is obligatory for the virus to infect the human host as this interaction will initiate a cascade of molecular mechanisms of the virus to hijack and proliferate the host. The virus then gains access to host cytosol by acid-dependent proteolytic cleavage of S-protein, followed by fusion of the viral and host cell membranes, which enables the release of the viral RNA into the cytoplasm of the host [32]. Upon RNA entry into the cell, the replication of viral genome is of utmost priority. For this, about $65 \%$ of the viral genome encodes RdRp 
Fig. 1 a Structure of SARSCoV-2 b Life cycle of SARS-

CoV-2 in human host (a) Structure

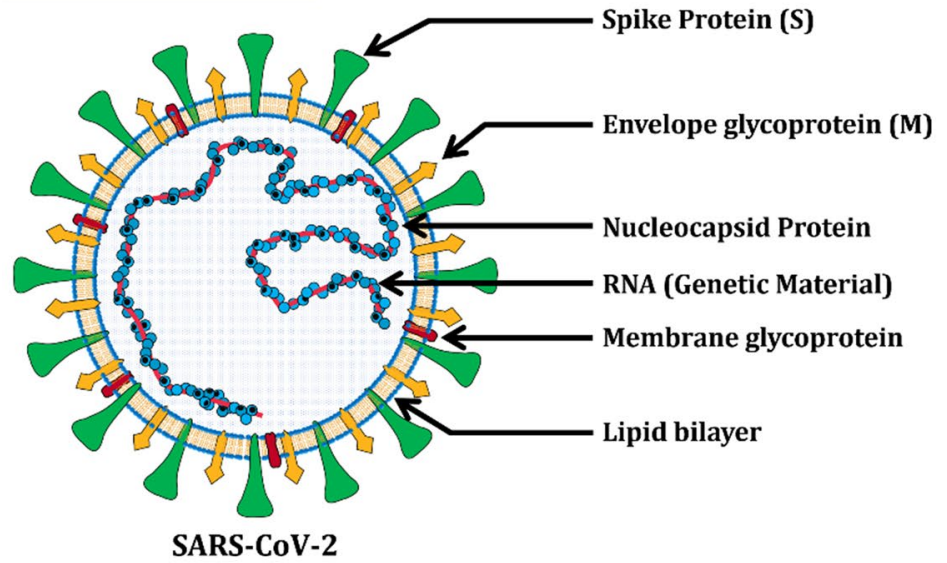

(b) Life Cycle

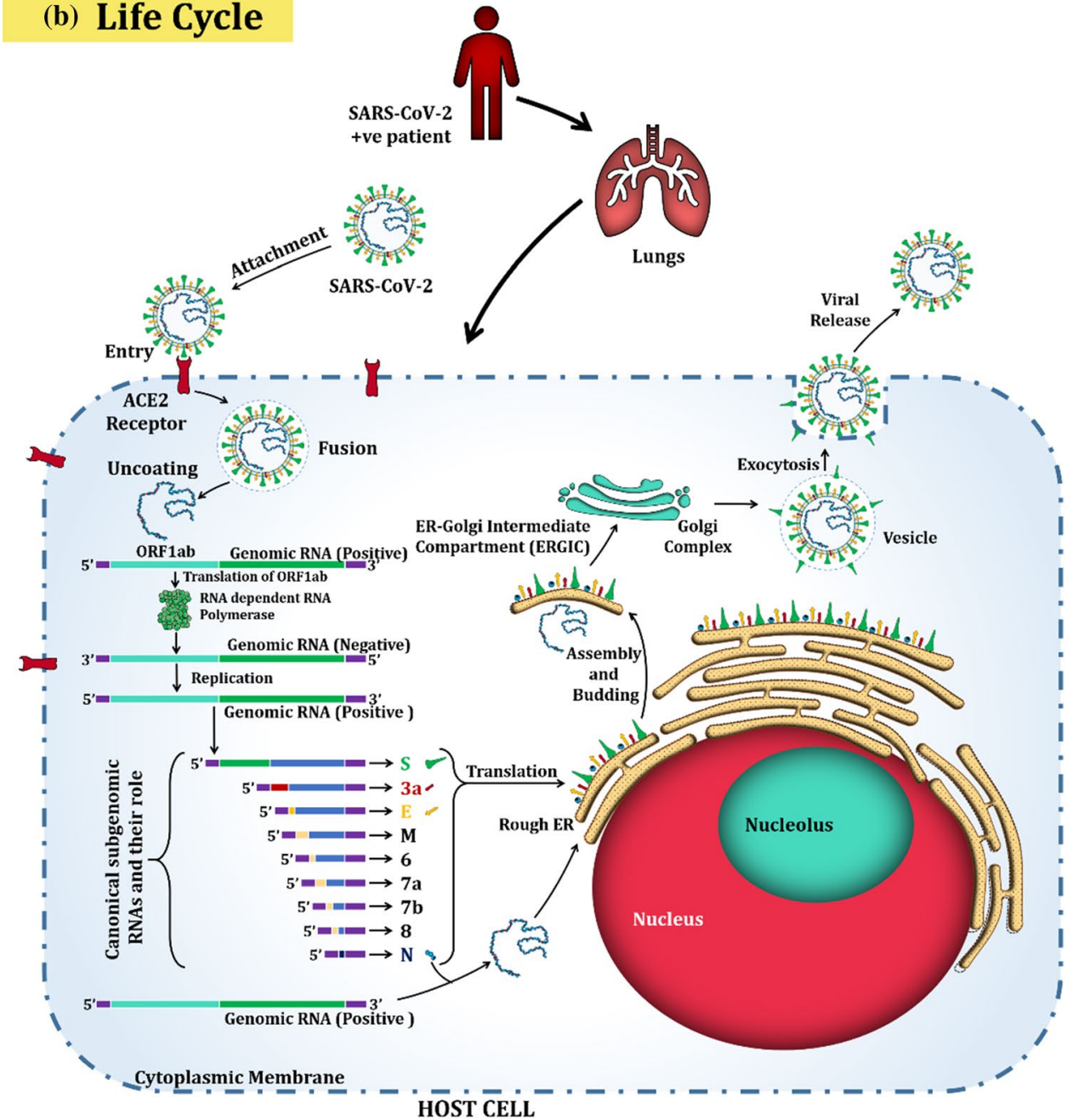

(replicase) polyproteins, composed of two large overlapping proteins pp1a and pp1ab. These proteins are acted upon by viral proteases, Main protease $\left(\mathrm{M}^{\mathrm{pro}}\right)$ and Papain-like protease $\left(\mathrm{PL}^{\mathrm{pro}}\right)$, to produce multiple polyprotein subunits that actively participate and facilitate viral replication and transcription. Protease $\mathrm{M}^{\text {pro }}$ is so named 'main' to reflect its 
continued engagement in processing replicase polyproteins and viral gene expression [33]. The first round of replication of (+) ssRNA would yield its complementary (-) ssRNA, which would serve as template for producing sub-genomic (+) ssRNA copies. Simultaneously, other proteins are being synthesized by discontinuous transcription [3].

\section{Diagnosis}

The first step towards curing of any ailment begins with its proper diagnosis. Initially thought to be an outbreak of influenza with the arrival of winter of 2019, an uncanny surge in number of cases of influenza-like illness (ILI) and other respiratory illnesses, was observed towards the last 45-50 days of 2019. Such atypical surge made it inevitable to distinguish influenza and COVID-19-infected individuals, and as a result, outpatients with a sudden onset of a fever of $>38^{\circ} \mathrm{C}$ and a cough or sore throat were investigated for the presence of SARS-CoV-2 [34]. Interestingly, in contrast to SARS-CoV, the occurrence of fever in novel SARS-CoV-2 infection was far more prevalent which made asymptomatic virus shedding a challenge for the authorities to distinguish the infected but asymptomatic and presymptomatic individuals; thus, thermal surveillance of individuals for detection, especially those exposed to a known place of
COVID-19 outbreak, was reviewed in favour of bringing in more reliable and accurate tests [13], (Figs. 2 and 3).

The symptoms, initially thought to be characteristic for SARS-CoV-2, included SARS-like viral pneumonia with milder illness [12, 35, 36]. The unavailability of rapid molecular diagnostic assays made it extremely difficult to accurately diagnose COVID-19 patients and thus tracking the transmission among a community [34]. Figure 4 illustrates the diagnostic methods currently being employed. Since the disease is inherently respiratory, the mucosal and sputum samples are collected from nasopharyngeal swabbing since the presence of SARS-CoV-2 would be apparent in these regions. A major drawback of sputum sample is its heterogeneity, which may lead to a false-positive reaction during RT-PCR. For this, a flexible extended swab is used, which may bend as per the contour of the cavity, and sample from deeper cavities of the nasopharynx could be collected. Bronchoalveolar lavage fluid (BALF) is also collected in addition to the throat swabs, followed by RT-PCR analysis $[30,37]$.

Urging to employ real-time RT-PCR method with specific primers and probes to detect the SARS-CoV-2 open reading frame $(\mathrm{ORF} 1 \mathrm{ab})$ and nucleoprotein $(\mathrm{N})$ gene regions, China CDC categorized an individual to be COVID-19 positive if both the molecular targets were

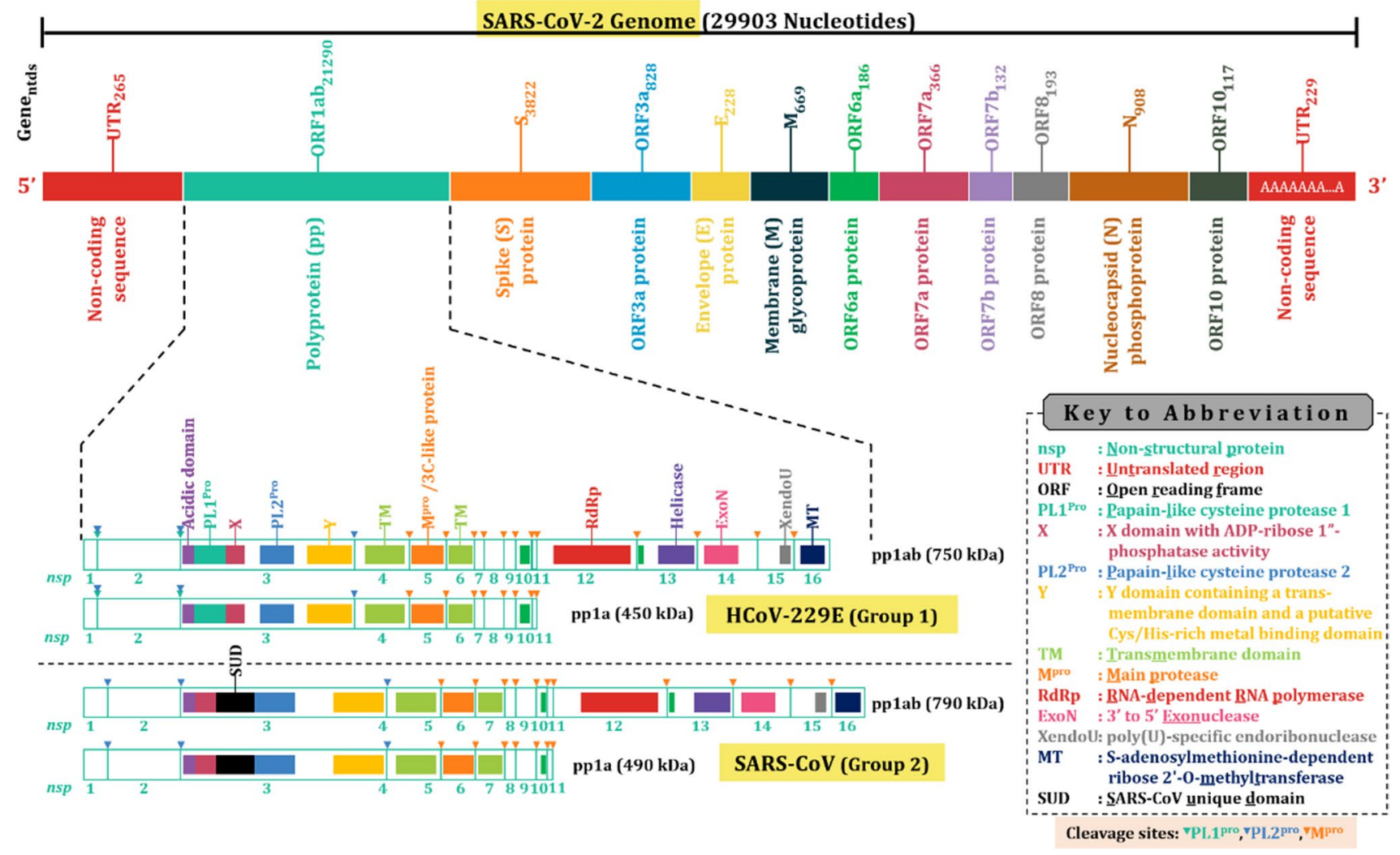

Fig. 2 Phylogenetic analysis to track lineage of SARS-CoV-2 with existing CoV 


\section{Phylogenetic Relationship}

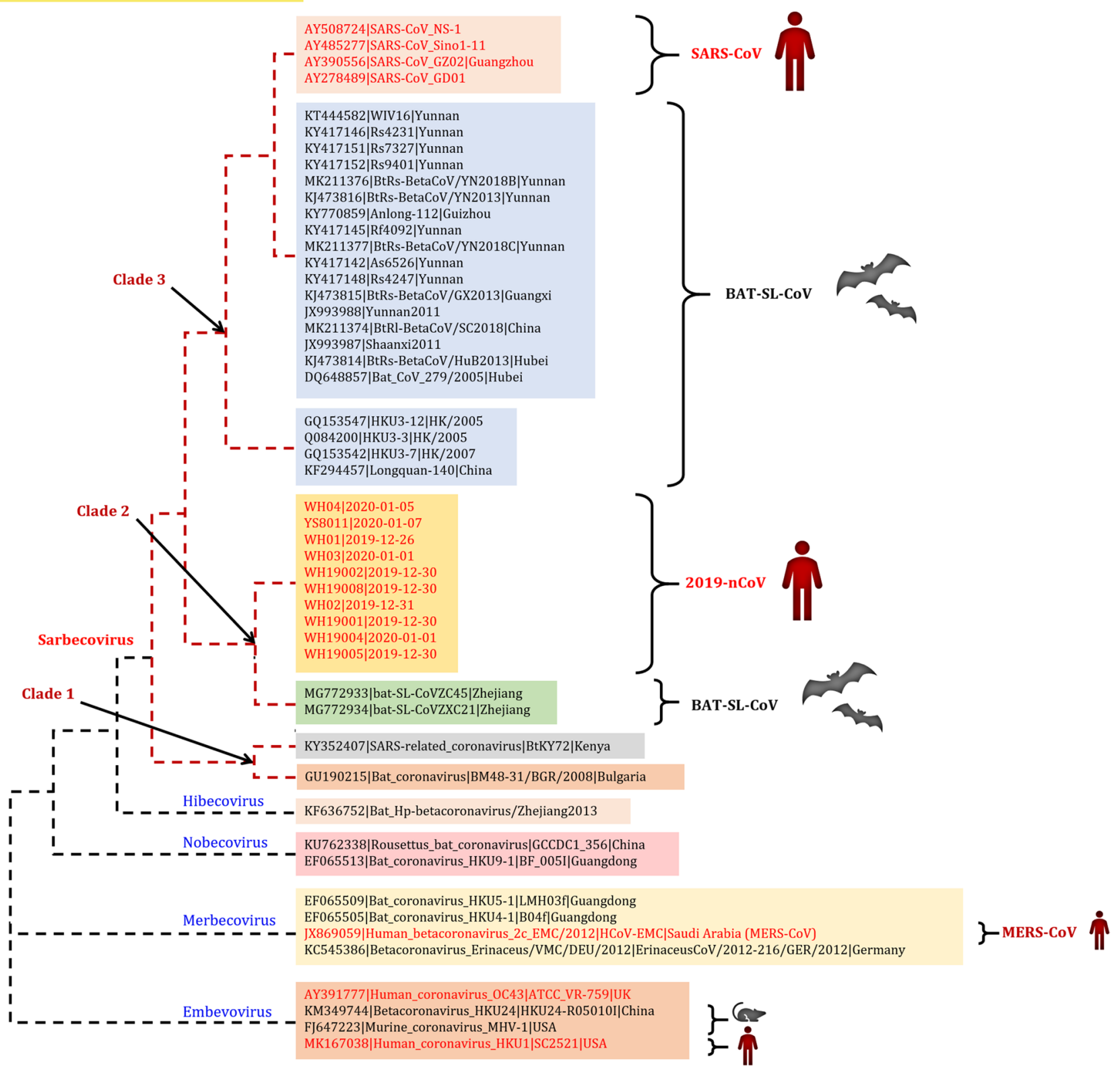

Fig. 3 Genome of SARS-CoV-2

positive [38]. As is the case with any diagnostic technique, a risk of a result being false-positive or false-negative overcasts the entire process and jeopardizes the prevention and control of an outbreak. A person testing negative for COVID-19 may have an underlying infection, while a COVID-19-positive individual may be co-infected with other pathogens, which may warrant a more coherent and holistic treatment. Thus, it was consequential to employ that other detection methods to screen for additional respiratory pathogens to discourage blind prescription and administration of drugs [39]. CT scans are used to detect any possibility of pneumonia as pleural effusion can be visualized as ground-glass-like opacity. Worryingly, asymptomatic patients can also manifest COVID-19 pneumonia with CT imaging. This calls for incorporation of CT scanning of suspected patients in tandem with other employed diagnostic techniques [40]. The IgG and IgM antibodies produced against SARS-CoV-2 S, N and proteins can be detected with the use of ELISA. Since the seroconversion for IgM antibodies normally occurs earlier than that of $\operatorname{IgG}$, such kits enable diagnosis of ongoing and past infections. Together with other detection techniques, 


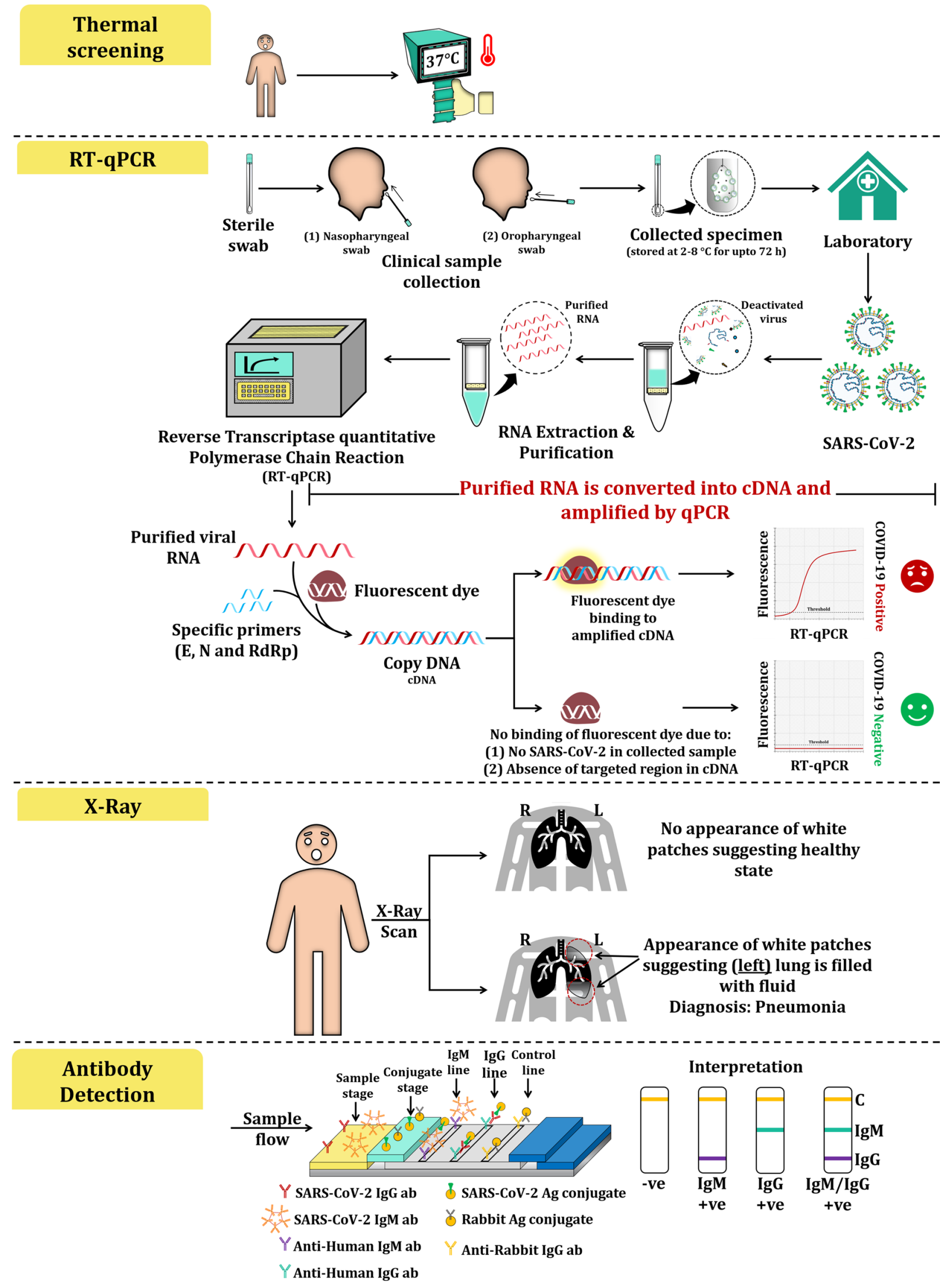

Fig. 4 Various diagnostic techniques employed for SARS-CoV-2 detection 
ELISA antibody detection ready-to-use kits would pave a path for a foolproof diagnosis of COVID-19 [13].

\section{Transmission}

Transmission of a pathogen helps in formulating preventive measures by the administration, to slow and stop a pathogen's occurrence and proliferation in a community. Droplet spread, in which the pathogen spreads via 'a relatively large, short-range aerosols produced by sneezing, coughing or even talking', is generally agreed upon mode of transmission of SARS-CoV-2 [41]. It is a direct transmission as a direct spray on a susceptible individual may make him infected. Mercifully, the mode of transmission is not airborne as the direct spray droplets fall on the ground after travelling a few feet in the air. An airborne transmission would have resulted in a much graver scenario and would have mandated the implementation of stringent and, at times, inconvenient methods of prevention and control [42, 43]. Another possible mode of transmission, the faecal-oral route is yet to be confirmed since such a transmission would have virtually overwhelmed third-world countries owing to their poor sanitary conditions.

\section{Prevention}

The use of face protectants such as masks to protect oneself from the direct spray of another person in addition to rigorous hand-washing with a soap or an alcohol-based sanitizer are the most commonly exercised preventive measures as per the recommendations of various health boards and ministries around the world. Social distancing or physical distancing has been unanimously recommended by the health-care advisories around the world as the most suitable method to avoid encountering the virus from another individual. Social distancing measures have led to the cancellation of routine academic or extracurricular sessions at schools, colleges and other educational institutes along with restrictions and bans in international and domestic travel with a complete ban in opening of gyms, bars, restaurants and other public places where people gather to socialize. Offices have been shut, and people have been advised to work-from-home. While highly inconvenient at first, the work-from-home has been incorporated into a habit by the individuals that require no or less physical in their workplace. People have been standing in queue while maintaining a distance of at least two metres to buy essentials from the store while embracing a non-contact way of greeting each other, ergo the handshake. Such measures have undoubtedly caused a dent in the economy and has halted the progress of various developing nations, one could only imagine the consequences had no such precautions been timely put forth.

\section{Treatment}

Since the inception of this virus, the researchers are trying to find targets that can be downregulated to stop its replication in host. Although the mortality rate of COVID-19 is in steep contrast to its $R_{0}$ value, with about 2 to 4 deaths per cent, about one in every four patients require intensive care unit (ICU) admission. An individual with an already weakened health, such as those with chronic heart disease, renal diseases and diabetes, is most susceptible as pneumonia is the most severe consequence of COVID-19, followed by acute respiratory distress syndrome (ARDS) [30]. Such patients are already following a strict medicinal routine which makes formulation with any other therapy more time-consuming as any wrong combination may impart a damage far more serious than, if not like that of COVID-19. Nevertheless, the hospitalized patients are subject to a more supportive care, i.e. maintaining proper oxygenation, ventilation and fluid management [44].

Low-dose antiviral treatments of ribavirin, interferons, corticosteroids and immunoglobulins are currently administered for the treatment. Recently, remdesivir is being administered to block the replication of SARS-CoV-2 in host. The drug is an analog of a nucleotide adenosine, which attaches itself between the RNA and induces premature termination of replication. It interferes with RdRp to escape proofreading, which ultimately causes a decrease in viral RNA production. In the past, remdesivir has successfully prevented the viral replication in MERS-CoV while reducing lung damage [45]. However, the antiviral drug is currently proposed as a post-infection treatment to avoid relapse of COVID-19. Other antiviral drugs under consideration are ribavirin, protease inhibitors lopinavir and ritonavir, interferon $\alpha 2 b$, interferon $\beta$, chloroquine phosphate and arbidol [13]. Drugs with antiviral and anti-inflammatory properties are also being screened and tested that reduce viral infectivity, replication and neutralize the host's inflammatory response [46].

While millions are infected, there are thousands across the globe that have successfully recovered from COVID-19. A Chinese report claims that such immunoglobulin therapy has yielded an improved oxygenation, reduced inflammation and viral load when administered in SARS-CoV-2-infected patients. The idea is simple and fundamental, a greater concentration of specific antibodies could effectively fight the virus, destroy its structural and functional integrity while facilitating complement activation for the host to prevail in the end. Such plasma therapy would also add to the existing memory of the host immune system to successfully ward off any subsequent exposure to SARS-CoV-2 virus particles [44]. In practical usage, such a therapy also poses a grave risk of increased thrombotic event risk [47]. This, in combination with the high recombination rate of the virus, 
demands utmost caution and elaborates clinical trials of the serum therapy before being applied.

\section{Futuristic strategies}

There are two ventures to control CoV (i) discover inhibitors to block virus entry into the host cells and (ii) discover bioactive compounds that prevent viral replication and transcription. In total, twelve proteins are identified as a target to control $\mathrm{CoV}$ of which $\mathrm{M}^{\text {pro }}$ is identified as one of the most vital targets, which plays a pivotal role in mediating viral replication and transcription $[48,49]$. The $\mathrm{M}^{\text {pro }}$ is a chymotrypsin-like cysteine protease $(\sim 33 \mathrm{kDa})$, and it is termed the main protease because of its dominant role in processing replicase polyproteins and gene expressions $[33,50]$. Recently, the structure of SARS-CoV-2 is solved recently by Jin and colleagues [48] and also proved that it shares the maximum similarity with SARS-CoV and relative similarity with MERS-CoV.

\section{Psychological implications}

\section{Mental health concerns}

An accelerated spread of the contagious coronavirus with an absence of proper treatment has posed challenges to community health and the health-care systems worldwide. With COVID-19 cases rising drastically, the preventive measures of social distancing, maintaining hygiene and isolation may have their own risks on mental health. The concern for retaining good mental health has become a task for mental health professionals and the society at large. Daily news, flashing the multiplying numbers of COVID-19 cases, has managed to amplify fear and anxiety of being infected and spreading infection resulting in either voluntary or forced quarantine [51]. While most of the people are not directly exposed to the epidemic areas, mere information on the severity of the virus transmission can magnify the psychological distress [52-54].

Studies among the general population of China during COVID-19 outbreak found high frequency in the emotions of anxiety, distress, specific phobias, loss of social functioning, avoidance and compulsive behaviour, especially higher in females and young participants $[54,55]$. Linear regression in another study showed anxiety and depression scores (DASS) to be significantly associated with the symptoms of sore throat, cough, breathing difficulty in normal population [56]. A survey conducted in 34 hospitals of China at the time of COVID-19 outbreak, on 1257 health-care workers aged between 26 and 40 years (64.7\%); 764 (60.8\%) nurses, 493 (39.2\%) physicians; 760 $(60.5 \%)$ worked in hospitals in Wuhan and $522(41.5 \%)$ frontline health-care workers reported symptoms of anxiety $(50.4 \%)$, depression $(44.6 \%)$, insomnia (34\%) and distress (71.5\%) [57]. Figure 5 illustrates various segregation of groups of individuals based on their exposure to COVID-19. Significant PTSD symptoms were found in health-care workers involved in treating COVID-19 patients as reported by a study in Singapore, which was surprisingly estimated to be 3 times lower than the PTSD symptoms found during the previous SARS outbreak (Impact of Event Scale) [58]. This could be attributed to increased mental preparedness and stringent infection control measures after Singapore's SARS experience [59].

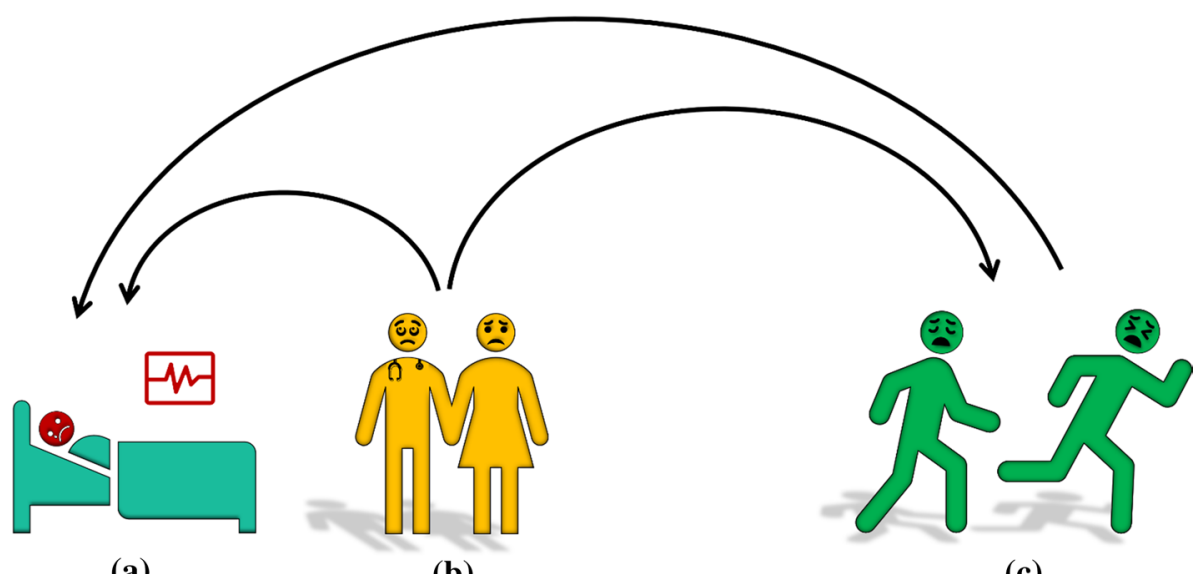

(a)

(b)

(c)

Fig. 5 Arrows indicate the wave of fear and anxiety in three groups; a infected patients, b Group working closely with infected patients or in epidemic areas (health-care workers, sanitization staffs and administrators), c Group away from the direct exposure, lock down at homes. [Group B shows (i) high anxiety of being infected and becoming $\mathrm{A}$ and (ii) fear of going back home and infecting the Group C. It was found that Group $\mathrm{C}$ although being less exposed as compared to Group B had high levels of anxiety of turning into Group A.] 


\section{Cabin fever}

Abiding by the lockdown rules unanimously is praiseworthy and commendable; however, its increased duration may become a challenge, emotionally and financially, resulting into cabin fever [51, 60]. The feeling of being trapped and loss of control have elevated with the cut down on daily activities of attending school; outdoor games, work, malls, theatres, eat-outs and any kind of mass gathering [61]. Decreased public contact, loss of routine and increased household tensions during confinement have frequently shown to cause frustration, boredom, irritability, anger, confusion, feeling of restlessness and dissatisfaction [62-65]. Daily wage migrants living in small, high-risk, cluster areas of the city or migrant camps are especially afraid and distressed about zero earning, of being infected, on struggling for food, about the inability to send money to family members and above all helpless of not being able to return back to their villages. Long duration of such a struggle somewhere also results into breaking of norms and violence [66, 67].

Social dilemma is an intrinsic conflict between a person's individual self-interest and the good of the group. The time of crises may demonstrate the strangest part of human nature. At the time of this infectious crisis, people move towards panic buying, overestimating their needs, chiefly resisting the very social distancing behaviours that may shield their health [68]. While on the one side, the behaviour patterns are changing towards avoiding people outrightly, decline in public trust, vigorous hand-washing, high-risk perception towards the uncertainty of who might just be a carrier of the virus [65, 69], on the other side, altruistic behaviours like helping people in need either by sharing food, donating money, volunteering in fumigation process, promoting home-stay plus hygiene with humour and drama in epidemic areas have been overwhelming on humanitarian grounds [70]. There is a need for physicians, psychiatrists, psychologists and social workers to come together virtually and develop interventions to psycho-educate the community through online forums about the knowledge, prevention and control of corona virus, about the best ways to utilize the quarantine period and about the online network for social support [71]. Technology can be best utilized to improve social skills, enhance social support by staying in contact with family and friends reducing the effects of isolationlike loneliness [72]. For students, teaching can be continued on web-based applications by the education authorities to reduce the negative effects of isolation [56].

\section{The way ahead}

It is undoubtedly a difficult time but as confusion and uncertainty prevail, there certainly is chaos but also hope. Scientists and doctors around the world are using the internet to publish information faster than ever before. This has yielded some potential solutions while we wait for a vaccine that could be over a year away. Vaccines must go through many clinical and testing stages before they are deemed safe to be administered. As for the psychological implications, an appreciable change in the lifestyle of people may be observed after the conclusion of lockdown and containment periods. Formation of a psychological rescue team to carry out a quick psychological first aid, helping people recognize their emotions at the time of crises and strategies of dealing with them. Higher awareness and access to virtual counselling and psychotherapeutic sessions by trained psychologists to address both pre-existing mental health issues and issues related to COVID-19 would help rehabilitate the mental health of the community in the long term. We must understand, with a grain of salt that, the spread of COVID-19 was essentially a lapse in our individual judgement of personal hygiene. Ideally, the chain of spread could have been broken had every individual made sure of the cleanliness and sanitation. Nevertheless, as resilience is the nature, humans as a species will rise-probably wiser, smarter and cleaner.

\section{Compliance with ethical standards}

Conflict of interests The authors have no conflict of interest to declare.

\section{References}

1. Organization WH. Coronavirus disease (2019) World Health Organization. https://www.who.int/emergencies/diseases/novel -coronavirus-2019. Published 2020. Accessed 18th Nov., 2020

2. Organization WH. WHO I SARS (Severe Acute Respiratory Syndrome). https://www.who.int/ith/diseases/sars/en/. Published 2020. Accessed 28, 2020

3. Sahin AR, Erdogan A, Agaoglu PM et al (2020) 2019 Novel Coronavirus (COVID-19) outbreak: a review of the current literature. Eurasian J Med Oncol 4(1):1-7

4. XinhuaNET (2020) China detects large quantity of novel coronavirus at Wuhan seafood market. http://www.xinhuanet.com/engli sh/2020-01/27/c_138735677.htm. Published 2020. Accessed 28th April, 2020

5. Neuman BW, Adair BD, Yoshioka C et al (2006) Supramolecular architecture of severe acute respiratory syndrome coronavirus revealed by electron cryomicroscopy. J Virol 80(16):7918-7928

6. Bárcena M, Oostergetel GT, Bartelink W et al. (2009) Cryoelectron tomography of mouse hepatitis virus: insights into the structure of the coronavirion, 106(2): 582-587

7. Fehr AR, Perlman S (2015) Coronaviruses: an overview of their replication and pathogenesis. In: Maier H, Bickerton E, Britton 
P (eds) Coronaviruses. Methods in molecular biology, vol 1282. Humana Press, New York, pp 1-23

8. Vijaykrishna D, Smith GJ, Zhang JX, Peiris J, Chen H (2007) Guan YJJov. Evolut Insights Ecol Coronaviruses 81(8):4012-4020

9. Cui J, Han N, Streicker D et al. (2007) Evolutionary relationships between bat coronaviruses and their hosts, 13(10): 1526

10. Gouilh MA, Puechmaille SJ, Gonzalez J-P, et al. (2011) SARSCoronavirus ancestor's foot-prints in South-East Asian bat colonies and the refuge theory, 11(7): 1690-1702

11. Lu R, Zhao X, Li J et al (2020) Genomic characterisation and epidemiology of 2019 novel coronavirus: implications for virus origins and receptor binding. Lancet 395(10224):565-574

12. Huang C, Wang Y, Li X et al (2020) Clinical features of patients infected with 2019 novel coronavirus in Wuhan, China. Lancet 395(10223):497-506

13. Yuen K-S, Ye Z-W, Fung S-Y, Chan C-P, Jin D-YJC (2020) bioscience. SARS-CoV-2 and COVID-19: The most important research questions, 10(1):1-5

14. Bai Y, Yao L, Wei T et al (2020) Presumed asymptomatic carrier transmission of COVID-19. JAMA 323(14):1406-1407

15. Wu JT, Leung K, Leung GM (2020) Nowcasting and forecasting the potential domestic and international spread of the 2019-nCoV outbreak originating in Wuhan, China: a modelling study. Lancet 395(10225):689-697

16. Corman VM, Muth D, Niemeyer D, Drosten C (2018) Hosts and sources of endemic human coronaviruses. In: Advances in virus research. vol 100. Elsevier; 2018, pp 163-188

17. Andersen KG, Rambaut A, Lipkin WI, Holmes EC, Garry RF (2020) The proximal origin of SARS-CoV-2. Nat Med 26(4):450-452

18. Nieto-Torres JL, DeDiego ML, Verdia-Baguena C et al (2014) Severe acute respiratory syndrome coronavirus envelope protein ion channel activity promotes virus fitness and pathogenesis. PLoS Pathog 10(5):e1004077

19. Cornelissen LA, Wierda CM, van der Meer FJ et al (1997) Hemagglutinin-esterase, a novel structural protein of torovirus. J Virol 71(7):5277-5286

20. Chin AW, Poon LL (2020) Stability of SARS-CoV-2 in different environmental conditions-Authors' reply. Lancet Microbe 1(4):e146

21. Van Doremalen N, Bushmaker T, Morris DH et al (2020) Aerosol and surface stability of SARS-CoV-2 as compared with SARSCoV-1. N Engl J Med 382(16):1564-1567

22. Xu XW, Wu XX, Jiang XG et al (2020) Clinical findings in a group of patients infected with the 2019 novel coronavirus (SARS-Cov-2) outside of Wuhan, China: retrospective case series. BMJ 368:m606

23. Zhou F, Yu T, Du R et al (2020) Clinical course and risk factors for mortality of adult inpatients with COVID-19 in Wuhan, China: a retrospective cohort study. Lancet 395(10229):1054-1062

24. To KK, Tsang OT, Leung WS et al (2020) Temporal profiles of viral load in posterior oropharyngeal saliva samples and serum antibody responses during infection by SARS-CoV-2: an observational cohort study. Lancet Infect Dis 20(5):565-574

25. Chen Y, Shan K, Qian W, Qian W (2020) Asians do not exhibit elevated expression or unique genetic polymorphisms for ACE2, the cell-entry receptor of SARS-CoV-2. In: Preprints

26. Chen Y, Li L (2020) SARS-CoV-2: virus dynamics and host response. Lancet Infect Dis 20(5):515-516

27. Pan Y, Zhang D, Yang P, Poon LLM, Wang Q (2020) Viral load of SARS-CoV-2 in clinical samples. Lancet Infect Dis 20(4):411-412

28. Weiss SR, Leibowitz JL (2011) Coronavirus pathogenesis. In: Advances in virus research, vol 81. Elsevier, pp 85-164

29. Woo PC, Huang Y, Lau SK, Yuen KY (2010) Coronavirus genomics and bioinformatics analysis. Viruses 2(8):1804-1820
30. Liu Y, Yang Y, Zhang C et al (2020) Clinical and biochemical indexes from 2019-nCoV infected patients linked to viral loads and lung injury. Sci China Life Sci 63(3):364-374

31. Tse GM, To KF, Chan PK et al (2004) Pulmonary pathological features in coronavirus associated severe acute respiratory syndrome (SARS). J Clin Pathol 57(3):260-265

32. Bosch BJ, van der Zee R, de Haan CA (2003) Rottier PJJJov. The coronavirus spike protein is a class I virus fusion protein: structural and functional characterization of the fusion core complex. 77(16):8801-8811

33. Yang H, Bartlam M (2006) Rao ZJCpd. Drug Design Targeting the Main Protease, the Achilles' Heel of Coronaviruses 12(35):4573-4590

34. Kong WH, Li Y, Peng MW et al (2020) SARS-CoV-2 detection in patients with influenza-like illness. Nat Microbiol 5(5):675-678

35. Chan JF, Yuan S, Kok KH et al (2020) A familial cluster of pneumonia associated with the 2019 novel coronavirus indicating person-to-person transmission: a study of a family cluster. Lancet 395(10223):514-523

36. Novel CPEREJZlxbxzzZlz (2020) The epidemiological characteristics of an outbreak of 2019 novel coronavirus diseases (COVID19) in China, 41(2): 145

37. Chu DKW, Pan Y, Cheng SMS et al (2020) Molecular Diagnosis of a Novel Coronavirus (2019-nCoV) Causing an Outbreak of Pneumonia. Clin Chem 66(4):549-555

38. Prevention NIfVDCa (2020) New coronavirus nucleic acid detection primer and probe sequence. http://ivdc.chinacdc.cn/ kyjz/202001/t20200121_211337.html. Published 2020. Accessed 28th April, 2020

39. Wang M, Wu Q, Xu W, et al. (2020) Clinical diagnosis of 8274 samples with 2019-novel coronavirus in Wuhan

40. Shi H, Han X, Jiang $\mathrm{N}$ et al (2020) Radiological findings from 81 patients with COVID-19 pneumonia in Wuhan, China: a descriptive study. Lancet Infect Dis 20(4):425-434

41. Prevention CfDCa (2020) Principles of Epidemiology I Lesson 1 - Section 10. https://www.cdc.gov/csels/dsepd/ss1978/lesson1/ section10.html. Published 2020. Accessed 28th April, 2020

42. West JS, Atkins SD, Emberlin J, Fitt BD (2008) PCR to predict risk of airborne disease. Trends Microbiol 16(8):380-387

43. Brickner PW, Vincent RL, First M, Nardell E, Murray M, Kaufman WJPHR (2020) The application of ultraviolet germicidal irradiation to control transmission of airborne disease: bioterrorism countermeasure

44. Cunningham AC, Goh HP, Koh D (2020). Treatment of COVID19: old tricks for new challenges. In: Springer

45. Gordon CJ, Tchesnokov EP, Feng JY, Porter DP, Gotte M (2020) The antiviral compound remdesivir potently inhibits RNAdependent RNA polymerase from Middle East respiratory syndrome coronavirus. J Biol Chem 295(15):4773-4779

46. Stebbing J, Phelan A, Griffin I et al (2020) COVID-19: combining antiviral and anti-inflammatory treatments. Lancet Infect Dis 20(4):400-402

47. Menis M, Sridhar G, Selvam N et al. (2013) Hyperimmune globulins and same-day thrombotic adverse events as recorded in a large healthcare database during 2008-2011, 88(12):1035-1040

48. Jin Z, Du X, Xu Y, et al. (2020) Structure of Mpro from COVID19 virus and discovery of its inhibitors

49. Kong R, Yang G, Xue R, et al. (2020) COVID-19 Docking Server: An interactive server for docking small molecules, peptides and antibodies against potential targets of COVID-19. J arXiv preprint

50. Yang H, Xie W, Xue X et al (2005) Design of wide-spectrum inhibitors targeting coronavirus main proteases. PLoS Biol 3(10):e324 
51. Lima CKT, Carvalho PMM, Lima I et al (2020) The emotional impact of Coronavirus 2019-nCoV (new Coronavirus disease). Psychiatry Res 287:112915

52. Shultz JM, Baingana F, Neria YJJ (2015) The 2014 Ebola outbreak and mental health: current status and recommended response, 313(6): 567-568

53. Bao Y, Sun Y, Meng S, Shi J, Lu L (2020) 2019-nCoV epidemic: address mental health care to empower society. Lancet 395(10224):e37-e38

54. Liu D, Ren Y, Yan F, et al. (2020) Psychological Impact and Predisposing Factors of the Coronavirus Disease 2019 (COVID-19) Pandemic on General Public in China

55. Qiu J, Shen B, Zhao M, Wang Z, Xie B, Xu YJGp (2020) A nationwide survey of psychological distress among Chinese people in the COVID-19 epidemic: implications and policy recommendations. 33(2)

56. Wang C, Pan R, Wan X, et al. (2020) Immediate psychological responses and associated factors during the initial stage of the 2019 coronavirus disease (COVID-19) epidemic among the general population in China. 17(5):1729

57. Lai J, Ma S, Wang Y, et al. (2019) Factors associated with mental health outcomes among health care workers exposed to coronavirus disease 2019. 3(3): e203976-e203976

58. Chan AO, Huak CY (2004) Psychological impact of the 2003 severe acute respiratory syndrome outbreak on health care workers in a medium size regional general hospital in Singapore. Occup Med Lond 54(3):190-196

59. Tan BYQ, Chew NWS, Lee GKH et al. (2020) Psychological Impact of the COVID-19 Pandemic on Health Care Workers in Singapore. Ann Intern Med

60. Hawryluck L, Gold WL, Robinson S, Pogorski S, Galea S, Styra R (2004) SARS control and psychological effects of quarantine, Toronto, Canada. Emerg Infect Dis 10(7):1206-1212

61. Rubin GJ, Wessely S (2020) The psychological effects of quarantining a city. BMJ 368:m313

62. Maunder R, Hunter J, Vincent L et al (2003) The immediate psychological and occupational impact of the 2003 SARS outbreak in a teaching hospital. CMAJ 168(10):1245-1251

63. Lee S, Chan LY, Chau AM, Kwok KP (2005) Kleinman AJSs, medicine. Experience SARS-related Stigma at Amoy Gardens 61(9):2038-2046
64. Braunack-Mayer A, Tooher R, Collins JE, Street JM, Marshall HJBph (2013) Understanding the school community's response to school closures during the H1N1 2009 influenza pandemic, 13(1):344

65. Brooks SK, Webster RK, Smith LE, et al. The psychological impact of quarantine and how to reduce it: rapid review of the evidence. 2020

66. Hargreaves S, Kumar BN, McKee M, Jones L, Veizis A (2020) Europe's migrant containment policies threaten the response to covid-19. In: British Medical Journal Publishing Group

67. Musa GU. COVID-19: The Global Pandemic and Cities' Resiliencel Godswill Unekwuojo Musa (GUMS)

68. report Hs (2020) Managing and understanding mental health concerns during the COVID-19 pandemic. https://hub.jhu. edu/2020/04/06/dani-fallin-mental-health-challenges-coronaviru s. Published 2020. Accessed 28th April, 2020

69. Marjanovic Z, Greenglass ER, Coffey SJIjons (2007) The relevance of psychosocial variables and working conditions in predicting nurses' coping strategies during the SARS crisis: an online questionnaire survey,44(6): 991-998

70. Cava MA, Fay KE, Beanlands HJ, McCay EA, Wignall R (2005) The experience of quarantine for individuals affected by SARS in Toronto. Public Health Nurs 22(5):398-406

71. Zhang J, Wu W, Zhao X, Zhang WJPCM (2020) Recommended psychological crisis intervention response to the 2019 novel coronavirus pneumonia outbreak in China: a model of West China Hospital. 3(1):3-8

72. Masi CM, Chen HY, Hawkley LC, Cacioppo JT (2011) A metaanalysis of interventions to reduce loneliness. Pers Soc Psychol Rev 15(3):219-266

Publisher's Note Springer Nature remains neutral with regard to jurisdictional claims in published maps and institutional affiliations. 